\title{
Bacteriology of brain abscess - observations on 50 cases
}

\author{
V. LAKSHMI, R. R. RAO† and *I. DINAKAR \\ Departments of Microbiology and *Neurosurgery, The Nizam's Institute of Medical Sciences, Hyderabad 500482, \\ India
}

\begin{abstract}
Summary. The bacteriology of brain abscess is complex-both aerobic and anaerobic organisms are involved, and their incidence varies from centre to centre. In this study of 50 consecutive cases of brain abscess, the value of both modern imaging techniques and the timehonoured Gram's stain was demonstrated. The Gram's stain showed organisms in 41 cases $(82 \%)$ and culture was positive in 44 cases $(88 \%)$. Thirty cultures yielded pure aerobic growth: Staphylococcus aureus, $\beta$-haemolytic streptococci and Proteus spp. were predominant. Five cases gave mixed aerobic cultures, and in seven cases anaerobes were isolated. Of these, three showed a mixed aerobic and anaerobic flora. Mycobacterium tuberculosis was cultured from one of the samples, which had shown acid-fast bacilli on direct smear. $M$. fortuitum was cultured from one sample, although no organisms were seen in the gramstained preparation.
\end{abstract}

\section{Introduction}

Brain abscess is recognised as a form of intra-cranial suppuration that is curable surgically. ${ }^{1}$ The bacterial flora of brain abscess is usually a complex mixture of aerobes and obligate anaerobes. ${ }^{2}$ The nature of the bacterial flora, the location of the abscess and the mortality have been extensively studied both in India and elsewhere among different age groups. ${ }^{1-8}$ The present study had three objectives. Firstly we wished to ascertain the demography of brain abscess in a highly specialised institute, secondly, to emphasise the usefulness of an immediate Gram's stain report in helping the clinician make a rational choice of antibiotic therapy as soon as possible, and thirdly to correlate the latest imaging techniques with microscopy and culture in the diagnosis of brain abscess.

\section{Materials and methods}

The study included 50 patients admitted to the neurosurgical unit at the Nizam's Institute of Medical Sciences, Hyderabad, from January 1987 to July 1991. There were 41 male and 9 female patients with a wide age range of $<1-55$ years (table I). The diagnosis of brain abscess was based on clinical symptoms and signs, neurological examination and computerised tomography (CT) scan of the brain with and without contrast medium. Specimens of pus from the abscess were collected through a burr hole in 34 patients and by craniotomy excision in 16 patients. The pus samples were transported immediately to the microbiology laboratory for Gram's staining and culture. A microbiologist was present whenever a brain abscess was drained or excised, to report on the Gram's stain and to process the specimen for culture without delay.

\section{Bacteriological examination}

An immediate Gram's stain was performed on all the specimens of pus. A Ziehl-Neelsen stain was also done on one sample when a tuberculoma was suspected. All the samples were processed without delay. Aerobic organisms were isolated by inoculation of samples on to blood agar 5\%, MacConkey agar and into brain-heart infusion biphasic medium. These were incubated at $37^{\circ} \mathrm{C}$ for $24-48 \mathrm{~h}$. Two of the samples were also inoculated on to Lowenstein-Jensen medium. The isolates were identified by conventional techniques and their antibiotic sensitivity was tested. For anaerobic cultures, the specimens of pus were inoculated into $10 \mathrm{ml}$ of thioglycollate broth which

Table I. Age and sex distribution of brain abscess patients

\begin{tabular}{ccc}
\hline $\begin{array}{c}\text { Age group } \\
\text { (years) }\end{array}$ & Males & Females \\
\hline$<1$ & 1 & 2 \\
$3-10$ & 13 & 2 \\
$11-20$ & 12 & 2 \\
$21-30$ & 5 & 0 \\
$31-40$ & 3 & 2 \\
$41-50$ & 4 & 1 \\
$51-60$ & 3 & 0 \\
Total & 41 & 9 \\
\hline
\end{tabular}


had been pre-heated and cooled to remove dissolved oxygen. After inoculation the broth was layered with sterile liquid paraffin to a depth of $1 \mathrm{~cm}$ and incubated at $37^{\circ} \mathrm{C}$ for $48 \mathrm{~h}$. Subcultures from thioglycollate broth were made on blood agar and were incubated in an anaerobic jar. Anaerobic conditions were achieved by means of a Gaspak system (Dyanox/Dyanamicro, Bombay, India) used according to the manufacturer's instructions. Anaerobiosis was checked by the use of indicators and by the absence of growth of Pseudomonas aeruginosa on pre-reduced blood agar. Incubation lasted for $48 \mathrm{~h}$ at $37^{\circ} \mathrm{C}$. All isolates were identified as recommended by Sutter et al.. ${ }^{9}$ and were tested for aerotolerance.

\section{Results}

The signs most often found in the 50 patients were fever $(84 \%)$ and raised intracranial tension $(58 \%)$ (table II). Suppurative otitis media was the most common predisposing feature $(48 \%)$ followed by congenital heart disease $(18 \%)$. The most common site of brain abscess was the parietal region $(44 \%)$. Table III shows the incidence of the predisposing features in relation to the location of the abscess. Forty-six abscesses were single, two were multi-

Table II. Clinical presentation of patients with brain abscess

\begin{tabular}{lc} 
Symptom or sign & Number $(\%)$ of cases \\
\hline Fever & $42(84)$ \\
Raised intracranial & $29(58)$ \\
tension & \\
Focal convulsions & $4(8)$ \\
Tonic and clonic & $4(8)$ \\
movements & $5(10)$ \\
Cerebellar signs & $12(24)$ \\
Deafness & $4(8)$ \\
Aphasia & $19(38)$ \\
Loss of consciousness & $50(100)$ \\
Evidence by CT scan &
\end{tabular}

Table III. Location of abscess in relation to predisposing cause

\begin{tabular}{lccccc} 
& \multicolumn{5}{c}{ Number of abscesses related to } \\
Location & CSOM & CHD & PL & TR & UK \\
\hline Frontal & 4 & 2 & 0 & 0 & 2 \\
Temporal & 6 & 1 & 0 & 0 & 2 \\
Parietal & 8 & 4 & 4 & 1 & 5 \\
Occipital & 2 & 1 & 0 & 0 & 0 \\
Corebellar & 4 & 0 & 0 & 0 & 1 \\
Subdural & 0 & 1 & 2 & 0 & 0 \\
Total $\%$ \% & $24(48)$ & $9(18)$ & $6(12)$ & $1(2)$ & $10(20)$ \\
\hline
\end{tabular}

CSOM, chronic suppurative otitis media: CHD, congenital heart disease: PL, pulmonary lesion: TR. trauma; UK, unknown. loculated and in the remaining two patients multiple abscesses were seen on CT scan. The Gram's stain of 41 of 50 pus specimens revealed polymorphonuclear leukocytes and organisms, and all 41 samples were culture positive. One specimen contained many lymphocytes and a Ziehl-Neelsen stain revealed numerous acid-fast bacilli, which on culture proved to be $M$. tuberculosis. However, this case was later confirmed by histological examination to be a tuberculoma rather than an abscess. The organisms isolated on culture are shown in table IV. Six $(12 \%)$ of 50 specimens showed no organisms in the Gram's stain and five $(10 \%)$ were sterile on culture. M. fortuitum was grown on Lowenstein-Jensen's medium from one specimen.

\section{Discussion}

Brain abscess is a life threatening infection with a high mortality. ${ }^{4}$ It remains a serious diagnostic problem and a critical therapeutic challenge. ${ }^{1}$ The decrease in mortality from $7-50 \%$ in the 1970 s to $0-24 \%$ in the 1980 s can be attributed partly to the rapid diagnosis offered by radionuclide brain scanning and CT scanning, and partly to the addition of metronidazole to the antibiotic armamentarium against anaerobes. ${ }^{3.10 .11}$ In our study of 50 patients suspected of having brain abscess, Gram's stain revealed the presence of organisms in 41 of the samples examined, whereas 44 were culture-positive. This clearly indicates that the current imaging techniques are highly specific, and if combined with investigations such as simple Gram's staining and subsequent culturing of the organism, enable the neurosurgeon to treat brain abscess more rationally. The neurosurgeon is thus also encouraged to make use of the expertise of the microbiologist by submitting the pus specimen for Gram's stain and culture without delay. Narayanan $e t$ $a l .^{8}$ also investigated 16 cases in their study group by CT scan. Ayyagari et al. ${ }^{6.11}$ studied the bacteriology of brain abscess with special reference to anaerobic bacteria, but made no mention of the correlation between imaging techniques, Gram's stain and isolation of the organism in the laboratory. In our study, CT scan was helpful in locating the site as well as identifying the presence of multiple abscesses.

Chronic otitis media and paranasal sinusitis are important sources of intracranial suppuration leading to meningitis, subdural empyema or intracranial ab${\text { scesses. }{ }^{1-3.12-14} \text { Suppurative lung disease }}^{68.15}$ or congenital heart diseases with left to right shunts ${ }^{4.5 .15}$ may also predispose to brain abscess. In our series, 24 $(48 \%)$ of 50 abscesses were otogenic in origin. Nine $(18 \%)$ occurred in patients with congenital heart disease, six $(12 \%)$ in patients with pulmonary disease: one abscess was post-traumatic. No obvious focus was recognised in the remaining 10 patients. There was no instance of post-operative brain abscess. Our study showed preponderance of male patients, although we could not find any explanation for this observation. 
Table IV. Results of cultures

\begin{tabular}{|c|c|c|c|}
\hline Type of isolate & $\begin{array}{l}\text { Number } \\
\text { of cases }\end{array}$ & Bacterial species & $\begin{array}{c}\text { Number of } \\
\text { isolates }\end{array}$ \\
\hline Aerobes (single species) & 30 & $\begin{array}{l}\text { Staphylococcus aureus } \\
\beta \text {-Haemolytic streptococci* } \\
\alpha \text {-Haemolytic streptococci } \\
\text { Streptococcus pneumoniae } \\
\text { Proteus mirabilis } \\
\text { P. vulgaris } \\
\text { Klebsiella pneumoniae } \\
\text { Enterobacter sp. } \\
\text { Escherichia coli }\end{array}$ & $\begin{array}{r}11 \\
5 \\
3 \\
1 \\
3 \\
2 \\
2 \\
2 \\
1\end{array}$ \\
\hline Mixed aerobes & 5 & $\begin{array}{l}\text { K. pneumoniae }+ \\
P . \text { mirabilis } \\
\beta \text {-Haemolytic streptococci* }+ \\
P . \text { mirabilis } \\
\text { S. aureus }+ \\
\text { P. vulgaris } \\
\text { S. aureus }+ \\
\text { P. mirabilis }\end{array}$ & $\begin{array}{l}2 \\
1 \\
1 \\
1\end{array}$ \\
\hline Anaerobes only & 4 & $\begin{array}{l}\text { Peptostreptococcus sp. } \\
\text { Bacteroides fragilis }\end{array}$ & $\begin{array}{l}3 \\
1\end{array}$ \\
\hline Aerobes + anaerobes & 3 & $\begin{array}{l}\beta \text {-Haemolytic streptococcus* }+ \\
\text { B. fragilis } \\
\text { S. aureus }+ \\
\text { B. fragilis } \\
\text { Str. pneumoniae+ } \\
\text { P. mirabilis + } \\
\text { B. fragilis }\end{array}$ & $\begin{array}{l}1 \\
1 \\
1\end{array}$ \\
\hline Mycobacteria & 2 & $\begin{array}{l}\text { Mycobacterium tuberculosis } \\
\text { M. fortuitum }\end{array}$ & $\begin{array}{l}1 \\
1\end{array}$ \\
\hline Sterile cultures & 6 & & \\
\hline Total & 50 & & 44 \\
\hline
\end{tabular}

* Not belonging to Lancefield groups A or D.

A rational use of antibiotics depends on knowledge of the causative organisms and their sensitivity. An early Gram's stain of the aspirated pus from a brain abscess may provide useful information regarding therapy to the neurosurgeon. A positive gram-stained film indicates $>10^{5} \mathrm{cfu} / \mathrm{ml}$ of exudate. In our series the Gram's stain results correlated with culture results in $82 \%$ of cases and provided useful guidelines to the neurosurgeon in initiating appropriate antibiotic therapy. The aerobic organisms most frequently isolated were Staphylococcus aureus, $\beta$-haemolytic streptococci and Proteus spp.

Anaerobic cultures were positive in only seven of 50 cases studied. The culture positivity for anaerobic bacteria correlated well with smear examination. This low incidence of anaerobes in our series needs explanation. If we consider anaerobic culture techniques, it is possible that the various types of techniques adopted and standardised by different laboratories may be one reason for the varying incidences of isolation. ${ }^{4-8,10,11}$ Nevertheless, in our study all those pus samples from brain abscess cases which showed a positive Gram's stain also yielded positive cultures. Furthermore, the low mortality in our series (because of prompt treatment based on the presumptive evidence of imaging techniques and Gram's stain) supports the assumption that our anaerobic culture techniques are reasonably reliable. Ayyagari et al. ${ }^{11}$ reported that the mortality rate in their study group was $36.11 \%$ and further stated that "Metronidazole was employed as a therapeutic regime when anaerobes were isolated from the corresponding pus samples." This policy might have contributed to the high mortality rate, because the recovery of anaerobes in culture usually takes a long time. Most Indian workers have just stated that they followed standard bacteriological techniques using McIntosh Fildes jar, and have made no mention of the details of the technical procedures, nor of the correlation between imaging techniques, film positivity and culture confirmation. Another reason might be variations in the incidence of chronic suppurative otitis media (CSOM) in different geographical areas. ${ }^{16-18}$ Ayyagari et al.,${ }^{6,11}$ in their two separate studies, reported that $48.8 \%$ and $38.9 \%$ of brain abscesses were otogenic in origin in the same area within a span of 2 years. The incidence of anaerobes in CSOM varies from nil to $65 \% .^{6,13,17,18}$ Although other conditions such as congenital arteriovenous malformations, lung abscess, trauma and many as yet unknown factors predispose to the development of brain abscess, by and large, CSOM is the most frequent cause, with an incidence of $25-50 \%{ }^{6,16,19}$ Otogenic brain abscess has been reported very frequently by many Indian workers. In our study too, 24 of 50 cases had a history suggestive of a partially treated middle ear infection. 
In conclusion, our study emphasises that early recognition and diagnosis of brain abscess is mandatory to avoid a high mortality. The present improvement in the prognosis of brain abscess is due to modern imaging techniques for localisation of the abscess which allow drainage and to progress in bacteriology and chemotherapy. It should be realised that brain abscess is no less an emergency for a microbiologist than it is for a neurosurgeon and a promptly evaluated gram-stained film is of inestimable value. The yield of positive cultures will be high if prompt and meticulous attention is paid to microbiological techniques.

\section{References}

1. Samson DS, Clark K. A current review of brain abscess. Am J Med 1973: 54: 201-210.

2. Ingham HR, Selkon JB, Roxby CM. Bacteriological study of otogenic cerebral abscesses: chemotherapeutic role of metronidazole. BMJ 1977: 2: 991-993.

3. Chun $\mathrm{CH}$, Johnson JD, Hojstetter M, Raff MJ. Brain abscess. A study of 45 consecutive cases. Medicine 1986; 65: $415-431$.

4. Balaji NK, Sukumar IP, Raj MD, Abraham J, Mathai KV, Cherian G. Brain abscess in congenital cyanotic heart disease. $J$ Assoc Phvsicians India 1977; 25 : 517-521.

5. Fischer EG. McLennan JE, Suzuki Y. Cerebral abscess in children. Am J Dis Child 1981: 135: 746-749.

6. Ayyagari A, Pancholi VK, Kak VK et al. Bacteriological spectrum of brain abscess with special reference to anaerobic bacteria. Indian J Med Res 1983: 77: 182-186.
7. Chandramukhi A. Narayan Reddy GN, Hegde AS. Anaerobes and the brain. Indian $J$ Surg 1981; 43: 90-93.

8. Narayan K. Khare PM, Kelkar SS. Anaerobic bacteria in brain abscess, a review; observation of 18 consecutive cases. Indian J Pathol Microbiol 1989; 32: 57-61.

9. Sutter VL, Citron DM, Finegold SM. Wadsworth anaerobic bacteriology manual, 3rd edn. St Louis, CV Mosby and Co. 1980.

10. Mampalam TJ, Rosenblum ML. Trends in the management of bacterial brain abscesses: a review of 102 cases over 17 years. Neurosurgery 1988: 23: 451-458.

11. Ayyagari A, Pancholi VK, Kak VK et al. Role of anaerobes and chemotherapy in brain abscess. Indian J Pathol Microbiol $1985 ; 28: 1-6$.

12. Legg NJ. Intracerebral abscess. Br J Hosp Med 1979; 22 : 608-614.

13. Feidt $H$, Federspil $P$. Eigene Untersuchungen ùber das aktuelle Spektrum der pathogenen Keime bei der Otitis externa und der chronischen Mittelohrentzũndung. Larỵngorhinootologie 1989; 68: 401-406. (English abstract).

14. Stool $\mathrm{S}$. Otitis media. Update on a common, frustrating problem. Postgrad Med 1989;85: 40-47, 51, 53.

15. Gelfand MS, Stephens DS, Howell EI, Alford RH, Kaizer AB. Brain abscess: association with pulmonary arteriovenous fistula and hereditary hemorrhagic telangiectasia: report of three cases. Am J Med $1988 ; 85: 718-720$.

16. Cabenda SI, Peerbooms PGH, Van Asselt GJ, Feenstra L, van der Baan S. Serous otitis media (s.o.m.); a bacteriological study of the ear canal and the middle ear. Int $J$ Pediatr Otorhinolaryngol 1988; 16: 119-124.

17. Pushpa J, Usha H. Anaerobes in chronic suppurative otitis media. Indian J Pathol Microbiol 1981: 24 : 107-111.

18. Chopra AK, Saigal RK, Sashikanta, Palimar TL. Role of anaerobes in chronic suppurative otitis media. Proceedings, XXXVI Annual Conference of the Indian Association of Pathologists and Microbiologists. 1987: B-16.

19. Gokul EN, Chandramukhi A, Ravi Kumar R, Neelam K. Anaerobes in brain abscess and other central nervous system infections: a decade's experience. Abstracts, First Asian Congress on Anaerobic Bacteria in Health and Disease. 1987: 59 . 